\title{
Os efeitos dos investimentos público e privado em capitais físico e humano sobre o produto per capita dos municípios da região sul: uma análise em painéis de dados dinâmicos
}

Darlan Christiano Kroth Mestre em Economia pela Universidade Estadual de Maringá (PR). Professor da Universidade Federal da Fronteira Sul..

Joilson Dias

Professor Doutor do Programa de Pós-Graduaçấo em Economia da Universidade Estadual de Maringá (PR).

\section{Palauras-chave \\ crescimento econômico, capital humano, crédito bancário, municípios.}

Classificação JEL O40, I20, E44, R10.

\section{Key-words}

economic growth, human capital, banking credit, cities.

JEL classification $O 40, I 20$,

E44, R10.

\section{Resumo}

O objetivo do trabalho é mensurar, de forma dinâmica a contribuição dos capitais, físico e humano, sobre o produto per capita dos municípios da região Sul do Brasil, para o período de 1999/2004. O trabalho inova em dois pontos em relação à literatura revisada. O primeiro consiste na construção das variáveis: capital humano e variação no estoque de capital físico. Para o capital humano, utilizou-se metodologia de Koman e Marin (1999). Para o capital físico, adotou-se como proxies o nível de investimento privado através de empréstimos para investimentos do setor bancário - em conjunto com os investimentos públicos, por meio do investimento em capital nos municípios. A segunda inovação se refere ao emprego da metodologia econométrica em dados de painéis dinâmicos, proposta por Blundell e Bond (1998a). Os resultados demonstraram maior influência do capital humano no produto per capita dos municípios do Sul do Brasil no período.

\section{Abstract:}

The objective of this paper is to measure in a dynamic way the contributions of human and physical capital to the per capita output of the Brazilian southern municipalities during 1999 - 2004. This paper innovates in two aspects regarding the reviewed literature. The first aspect is related to the variables human and physical capital. The human capital was built according to the methodology proposed by Koman and Marin (1999). The investment in physical capital was obtained from four sources: public investment made by the governments at municipal level and private ones made through loans from the banking system. The second aspect regards the econometric technique. The paper uses the GMM (Generalized Method of Moments) proposed by Blundell and Bond (1998a). The main result is that the human capital showed to be the most important one for the period analyzed. 


\section{1_ Introdução}

Os estudos sobre crescimento econômico em nível de países e estados evoluíram recentemente a partir da construção de variáveis consideradas importantes, como as de capital físico e humano. Em relação aos municípios, essa evolução não aconteceu na mesma proporção na literatura, em função da falta dessas variáveis a esse nível de desagregação. Para o Brasil essa realidade não é diferente, e os poucos trabalhos existentes sobre crescimento econômico municipal concentram sua análise sobre o aspecto da convergência, não ewxplorando mais especificamente os fatores que determinam o crescimento dos municípios. Além dos trabalhos sob o prisma da convergência, podem ser citados ainda alguns trabalhos na área de economia regional aplicada que utilizam o instrumental de econometria espacial.

A vantagem dos estudos do âmbito municipal em relação ao agregado é que as cidades são totalmente abertas ao comércio, apresentando livre mobilidade para os fatores de produçáo. A proximidade de pessoas e firmas facilita a transferência de conhecimento entre indivíduos (capital social), sendo o núcleo microeconômico para a explicação do crescimento macro. Ao trabalhar com municípios, pode-se ainda isolar a interferência das instituições, bastante hetero- gênea entre países (como aspectos legal e contábil), e as políticas macroeconômicas, pois tal interferência se torna homogênea para todos os municípios do país.

Assim, ao trabalhar com municípios é possível captar mais realisticamente as heterogeneidades existentes entre eles e as advindas das suas políticas de acumulação de capital físico e humano. Porém, não se pode deixar de considerar que essa heterogeneidade entre os municípios sofre outras influências, como tamanho (municípios considerados polos regionais, que acabam atraindo maior volume de investimentos, dado apresentarem melhor infraestrutura, bem como maior oferta de mão de obra e matérias-primas), localização (proximidade a grandes centros e/ou rodovias e portos, que atraem investimentos devido à redução dos custos de transportes), colonização e cultura.

Dada a grande quantidade de fatores que podem influenciar o desempenho econômico dos municípios, a tarefa de isolá-los com o intuito de captar efeitos das variáveis de interesse exige a aplicação de técnicas avançadas. Este é um dos desafios desse artigo, ao utilizar painéis dinâmicos balanceados que permitem verificar as alteraçóes no tempo e entre os municípios decorrentes das variáveis que medem capital humano e físico, assim 
${ }^{1}$ RAIS-Relação Anual de Informaçôes Sociais. Para maiores detalhes veja em www.rais.gov.br. como controlar tecnicamente os efeitos das demais variáveis omitidas, sem causar vieses nos coeficientes estimados.

$\mathrm{O}$ interesse em investigar os fatores que contribuem para o desempenho econômico municipal decorre do fato de que, ao comparar as taxas de crescimento para o período de estudo, verificase uma grande disparidade na dinâmica dos municípios pertencentes à região Sul do Brasil, disparidade essa também observada para os demais municípios do país. Nesse cenário, observa-se que mais de um terço dos municípios do Sul obtiveram crescimento anual médio negativo (mais de 450 municípios). Esses resultados são contrastados com municípios que obtiveram verdadeiros milagres de crescimento, crescendo anualmente acima de 7\% (cerca de 60 municípios).

Nesse sentido, o presente trabalho chega com o intuito de contribuir com a literatura que trata do crescimento econômico dos municípios - proporcionando uma melhor compreensão da dinâmica dos municípios da regiáo Sul - e de explorar alguns determinantes de seu produto per capita. Para alcançar esses objetivos, foram elaboradas duas variáveis, apontadas como relevantes pela literatura de crescimento econômico, que permitem avaliar o crescimento do produto municipal per capita.
A primeira variável se refere ao estoque de capital humano, para a qual se utiliza a metodologia proposta por Koman e Marin (1999), tendo como insumo a base de dados da RAIS ${ }^{1}$. Estes autores seguiram Hall e Jones (1999), propondo a construção do estoque de capital humano a partir de uma função denominada Macro-Mincer. Essa nova metodologia foi considerada mais adequada que a de proxies como nível médio de escolaridade ou ainda investimento em educação per se, pois considera a experiência média da força de trabalho e seus coeficientes de produtividade associados a cada nível de educação.

A segunda questão importante está relacionada à variável capital físico dos municípios. Trabalhos como os de Ferreira e Malliagros (1998), Portugal e Souza (1999) e Chagas e Toneto Jr. (2003) utilizam normalmente o nível de consumo de energia elétrica como uma das proxies para investimento em capital físico. Neste artigo procurou-se inovar ao construir esses níveis de investimentos a partir da combinação dos investimentos públicos nos municípios advindos das esferas federal, estadual e municipal. A existência de dados públicos facilitou essa tarefa, mas restou o desafio de encontrar uma variável que pudesse representar os in- 
vestimentos privados. Para tanto foram levantados, junto ao Banco Central, os dados de financiamentos bancários realizados pelas empresas, que são utilizados para ampliação da capacidade produtiva. Assim, acredita-se captar os movimentos dos investimentos privados em aumentos da produção, quer seja em estoques quer seja em máquinas, equipamentos e infraestrutura. Portanto, o único aspecto que não será captado diretamente são os investimentos realizados pelas próprias empresas. Esta variável omitida será minimizada com o uso da técnica econométrica proposta.

Ressalta-se que a metodologia econométrica utilizada soluciona, além do aspecto de variáveis omitidas mencionado acima, outro importante critério, que é o da causalidade das variáveis. Essa técnica permite verificar se é a acumulação em períodos anteriores de capital físico e humano que está causando aumentos no desempenho econômico dos municípios e não o contrário, fato esse conhecido na literatura como causalidade reversa.

$\mathrm{O}$ emprego de painéis dinâmicos proposto neste trabalho permite obter coeficientes sem vieses, pois resolve o problema de causalidade reversa e das variáveis omitidas, segundo Blundell e Bond (1998a). Como instrumento, essa técnica utiliza-se de um sistema de equaçôes di- nâmicas em que as variáveis em nível defasadas são instrumentos da equação em diferença e as diferenças defasadas são instrumentos das variáveis da equação em nível. Esses instrumentos possibilitam estimar dinamicamente o sistema, eliminando a endogeneidade potencial entre as variáveis e reduzindo os efeitos de variáveis omitidas nas equaçóes dinâmicas.

Este estudo está dividido em cinco seções, além desta introdução. A primeira seção faz uma breve apresentação da evolução da literatura de crescimento econômico e apresenta alguns estudos empíricos sobre municípios. A segunda seção se preocupa em apresentar os aspectos relacionados com o capital humano, como: i) apresentação teórica da variável; ii) os trabalhos empíricos, dando ênfase à construção e utilização das proxies de capital humano e seus principais resultados; e, iii) explicação da construção da proxy de estoque de capital humano utilizada no presente trabalho. Na seção seguinte, explora-se a importância do sistema financeiro em favorecer a atividade econômica e são apresentados alguns trabalhos empíricos. A quarta seção discorre sobre a aplicação econométrica do trabalho, a qual compreende a fonte de dados utilizada, a metodologia de painéis de dados, testes e resultados das regressóes. A última parte é reservada para as consideraçóes finais. 


\section{Produtividade dos fatores e crescimento econômico}

Conforme Barro e Sala-i-Martin (1995), um aspecto chave que explica as variaçóes na taxa de crescimento econômico dos países se refere às diferenças na produtividade dos fatores de produção. A melhoria na produtividade decorre, conforme consenso da literatura, da ampliação do estoque de capital físico, juntamente com progresso tecnológico aliado à ampliação do capital humano. $\mathrm{O}$ capital humano participaria em dois aspectos, favorecendo a invenção tecnológica e tornando a mão de obra mais qualificada. Há ainda outras variáveis que encorajam um ambiente mais propício à realização de investimentos nesses capitais, que se referem à infraestrutura social, instituiçóes, estabilidade econômica, maior abertura ao comércio internacional, além de novos atributos que vêm ganhando espaço na literatura nos últimos anos, como a importância dada ao sistema financeiro.

$\mathrm{Na}$ literatura sobre crescimento econômico, um dos trabalhos pioneiros a explorar a interação dos fatores de produção (capital e trabalho) e a capacidade desses na geração de crescimento econômico foi o de Solow (1956), que retrata

${ }^{2}$ Considerando uma economia fechada, pois há também o investimento externo. que o crescimento é derivado, sobretudo, da acumulação do capital por trabalhador, destacando-se, como fator exógeno, a tecnologia. Embora a variável tecnologia seja a fonte do crescimento sustentado no longo prazo, ela não é explicada pelo modelo. A lacuna deixada por Solow motivou vários estudos, como os de Lucas (1988), Romer (1990) e Aghion e Howitt (1992), que buscaram explicar qual a origem desse progresso tecnológico. Esses trabalhos serão conhecidos como modelos endógenos de crescimento econômico, devido ao fato de inserirem a variável capital humano na função produção, endogeneizando assim a variável progresso técnico.

A equação 1 apresenta a função produção de forma genérica, evidenciando que o produto da economia $(Y)$ é função dos capitais físicos - divididos em público $\left(K_{p u}\right)$ e privado $\left(K_{p r}\right)$ - e dos fatores capital humano $(H)$ e tecnologia $(A)$.

$$
Y=f\left(K_{p u}, K_{p r}, A, H\right)
$$

A segmentação do capital físico em público e privado decorre da existência de dois tipos de investimentos na economia $^{2}$. O investimento público está mais voltado à formação de uma infraestrutura básica, como malha logística (rodovias, ferrovias e portos), pontes, redes de distribuição elétrica e de telecomunicaçóes, enquanto os investimentos privados são destinados à ampliação da 
capacidade produtiva, como aquisição de máquinas e equipamentos, construção de edificações e plantas industriais. Nesse sentido, o capital de infraestrutura pública complementaria o capital privado.

Dada essa complementaridade, a existência de uma infraestrutura local razoável torna o capital privado mais produtivo, ${ }^{3}$ além de gerar outros benefícios, como favorecer a redução dos custos de transação, o que contribui para gerar maiores retornos sobre o capital investido, sendo um estímulo para novos empreendimentos. Essa redução de custos acaba estimulando a atração de investimentos internos e externos; esse resultado tem sido confirmado por trabalhos empíricos apresentados pela literatura sobre crescimento econômico. ${ }^{4}$

Considerando essa importância do capital físico, a sua ampliação é função do nível de investimento, o qual depende da taxa de poupança. Nesse sentido, ao apontar a variável investimento como determinante do estoque de capital físico, surge o interesse em explorar os fatores responsáveis por estimular esses investimentos. Nessa conjuntura, ganhou espaço nas duas últimas décadas a importância dada ao setor financeiro, devido ao seu papel de transmissor de políticas monetárias e alocação de recursos para investimentos. A contribuição do sistema financeiro, segundo
Pagano (1993), está relacionada a favorecer o acúmulo de poupança e direcioná-lo para investimentos produtivos na economia. Esses investimentos contribuem, portanto, para o acúmulo dos estoques de capitais físico e humano, possibilitando também a geração de novas tecnologias e, assim, ganhos de produtividade para a economia.

Já o fator capital humano pode ser representado pelo crescimento exponencial da mão de obra associada aos seus anos de escolaridade, e multiplicada pelo fator retorno da educação. $\mathrm{O}$ fator retorno da educaçấo mede o quanto um trabalhador é mais eficiente (ou seja, mais produtivo) dado o seu maior grau de educação. Esses coeficientes são obtidos através de equação Minceriana, que será aprofundada juntamente com a literatura sobre capital humano, na seção 3 .

Verifica-se, portanto, como as variáveis capital físico e humano se inserem na função produção e possibilitam ganhos de produtividade para os fatores. $\mathrm{O}$ próximo tópico explora alguns trabalhos empíricos que analisam o crescimento econômico em âmbito municipal.

\section{1_Estudos empíricos sobre crescimento econômico municipal}

Conforme mencionado na introdução, os estudos sobre municípios possuem

\footnotetext{
${ }^{3}$ Ver Ferreira e Milliagros (1998), para o Brasil.

${ }^{4}$ Hall e Jones (1999) inserem a variável infraestrutura social na função produçáo, mas esta está relacionada com os seguintes fatores: abertura comercial e instituições/ legislação do país, que são responsáveis por criar um ambiente favorável para investimentos. No presente estudo, ao tratar do crescimento das cidades, esses dois aspectos são homogêneos, fazendo emergir a importância da infraestrutura pública local como fator que incentiva/favorece investimentos privados.
} 
${ }^{5}$ Os aspectos locacionais são tratados pela Nova Geografia Econômica, como se pode ver em Marques (2001) e Oliveira (2005).

${ }^{6}$ Uma rica discussão sobre convergência é encontrada em Barro e Sala-i-Martin (1995). um diferencial se comparados aos trabalhos sobre países, pois as cidades são totalmente abertas ao comércio, apresentando livre mobilidade para os fatores de produção entre si. Uma ressalva, porém, que é feita a esses estudos decorre da heterogeneidade existente entre os municípios, como é o caso do fator locacional. ${ }^{5}$ A metodologia de painéis empregada nesse trabalho contribui para a resolução desse problema, ao levar em consideração os efeitos fixos dos municípios.

Apesar da importância de compreender a dinâmica dos municípios, os estudos empíricos nessa área ainda são escassos, tanto internacional como nacionalmente. Em nível internacional, encontra-se o trabalho de Glaeser et al. (1995), no qual se verificou que o crescimento de cidades americanas para o período de 1960-1990 está positivamente relacionado ao nível inicial de escolaridade e negativamente relacionado com a taxa inicial de desemprego e com o nível de emprego na manufatura.

Para o Brasil, e especificamente para a região Sul, a falta de estudos na área é influenciada, sobretudo, pela precariedade estatística em nível municipal. Se considerarmos os estudos que tratam exclusivamente das variáveis apresentadas neste trabalho, a lacuna é ainda maior. A maioria dos trabalhos existentes direcionam suas análises para o aspecto da convergência, ${ }^{6}$ como os de Chagas e Toneto Jr. (2003) e Porto Junior e Ribeiro (2000).

No trabalho de Chagas e Toneto Jr. (2003) explorou-se o crescimento municipal para o período de 1980 a 1991, utilizando dados dos censos desse período e analisando um total de 3.991 municípios brasileiros. $\mathrm{O}$ resultado encontrado foi que a tese de convergência prevaleceu para os municípios brasileiros, tendo como principais fatores determinantes a renda inicial do município, a aglomeração de empresas de determinada indústria, os fatores geográficos e o estoque de capital humano.

No estudo de Porto Junior e Ribeiro (2000) verificou-se, para o período de 1970 a 1998, que a maioria dos municípios da regiáo Sul possui rendas abaixo da média regional e que eles não convergem para uma mesma renda média de longo prazo, situando-se numa armadilha de pobreza e necessitando de algum choque, a exemplo de investimentos públicos, para alterar favoravelmente a distribuição de renda.

Saindo do escopo da convergência há os trabalhos de Portugal e Souza (1999), nos quais se analisaram os fatores de crescimento dos três estados da regiáo Sul para o período de 1960 a 1995, diagnosticando que o principal fator de estímulo para os estados do Rio Grande do 
Sul e Santa Catarina se refere aos investimentos privados (elasticidades de $0,73 \mathrm{e}$ 0,33 , respectivamente). O capital humano, que considera os gastos em infraestrutura social básica (educação, cultura, saúde e saneamento), foi significativo apenas para o Rio Grande do Sul, com coeficiente de 0,35. Para o Paraná os fatores utilizados não se mostraram significantes.

O estudo de Nakabashi e Felipe (2007) avaliou a importância do capital humano na explicação da diferença no nível e na taxa de crescimento do PIB por trabalhador nos municípios paranaenses, para os anos de 1991 e 2000, verificando que para cada ano adicional de escola ocorre um aumento entre 5,15\% a 7,16\% no nível de renda por trabalhador (dependendo da metodologia econométrica utilizada).

Outros trabalhos que tratam especificamente de municípios são o de Oliveira (2005) e o de Pires (2005). O primeiro, ao investigar o crescimento dos municípios do Ceará na década de 1990, verificou que as variáveis que mais contribuíram para a geração de externalidades espaciais foram o capital humano e a taxa de urbanização. Já Pires constrói um modelo com a presença do setor financeiro, no qual encontra relação positiva entre esse e o crescimento dos municípios para o período de 1991 e 2000 , porém não trata da causalidade.
Apesar de escassos, os estudos que trataram de investigar o crescimento econômico dos municípios dão relevância à variável capital humano, e a proxy mais utilizada se refere aos anos de escolaridade da população acima de 25 anos. Outras variáveis consideradas nesses trabalhos estão relacionadas à infraestrutura (representada pela taxa de urbanização e/ou gastos em infraestrutura) e aos gastos do governo. Já a variável sistema financeiro, quando utilizada, foi representada pelos empréstimos bancários totais.

Para apresentar melhor as duas variáveis a serem utilizadas na presente pesquisa, e sua importância para o crescimento econômico, realiza-se nas próximas duas seçōes uma explanação da literatura e dos principais estudos empíricos sobre o capital humano e sobre o sistema financeiro (crédito) que se apresentam como as bases teóricas do presente trabalho.

\section{3_ O capital humano}

Seguindo o exposto por Dias e Dias (1999), a importância do capital humano para o crescimento econômico deriva da ideia de que os indivíduos com maior nível de conhecimento, e em consequência maiores habilidades, tornam-se mais produtivos, contribuindo para gerar um maior nível de produ- 
${ }^{7}$ Além da forma minceriana, há outra maneira de captar os retornos com educaçáo, como a técnica do valor presente. Mais detalhes desta metodologia podem ser vistos em Psacharopoulos (1993). ção, além de possibilitarem a inovação das técnicas de produção.

Essa importância do conhecimento vai ser destacada a partir da década de 1980, apesar de existirem muitos trabalhos anteriores sobre o tema. A literatura de capital humano pode ser dividida em duas áreas: a primeira, microeconômica, busca mensurar os retornos monetários para o indivíduo com investimentos em educação, tendo nos trabalhos de Mincer (1974) a principal referência. A segunda área, macroeconômica, procura explicar de que forma o capital humano contribui para gerar crescimento econômico, construindo assim modelos macroeconômicos que endogenizam esta variável.

Pelo lado microeconômico, sobressaem os trabalhos de cunho minceriano, que destacam que o tempo gasto em educação pelo indivíduo (anos de escolaridade) é responsável pela explicação da melhora de seus rendimentos, ou seja, indivíduos mais qualificados, que por isso são mais produtivos, auferem salários mais elevados. ${ }^{7}$

Psacharopoulos (1993) expóe que, dada a facilidade no tratamento da equação minceriana e a possibilidade de captar diferenças nos sistemas educacionais entre os países, o modelo minceriano é preferível e o mais utilizado na maioria dos trabalhos que buscam captar os re- tornos com a educação. Em sua maioria, esses estudos alcançaram coeficientes que variam de $5 \%$ a $15 \%$ para cada ano adicional de escolaridade, taxas essas que variam no tempo e para cada país. Entre os trabalhos que buscaram medir esses coeficientes destacam-se os de Psacharopoulos (1993), Lam e Schoeni (1993) e Sachsida et al. (2004).

Segundo Krueger e Lindahl (2001), os trabalhos mincerianos apontados acima captam apenas os retornos privados $\mathrm{da}$ educação, ou seja, os retornos monetários que o indivíduo alcança. Por outro lado, a educação é responsável também por gerar retornos sociais, pois promove externalidades positivas para a sociedade, como a inovação e a difusão tecnológicas, a maior participação nas decisōes políticas (melhoria das instituiçóes) e o desenvolvimento econômico. É nesse escopo que os trabalhos em nível macroeconômico focalizam sua preocupação.

$\mathrm{Na}$ área macroeconômica emergem os dois maiores benefícios gerados pelo capital humano: i) o incremento do nível educacional favorece a produção de ideias, que por sua vez serão transformadas em inovações tecnológicas, originando novos produtos, bem como melhoria nos processos produtivos, e; ii) o maior nível educacional aumenta a habilidade dos indivíduos, possibilitando-lhes a uti- 
lização de maior volume de capital/tecnologia, e tornando-os mais produtivos.

Para o primeiro aspecto, pode ser apontado o trabalho de Romer (1990) que demonstra que o capital humano é responsável pela criação do progresso tecnológico (devido aos investimentos em pesquisa e desenvolvimento), gerando ganhos de produtividade (retornos crescentes) e possibilitando, assim, o crescimento em longo prazo. A ideia de que o progresso tecnológico pode ser gerado pelo acúmulo de capital humano - endógeno, portanto, ao modelo - é a grande inovação perante o modelo de Solow.

Lucas (1988), no entanto, concentra seu estudo na segunda tese, retratando a ênfase dada ao capital humano como mão de obra mais produtiva. Essa seria uma explicação para os países que investem menos em educação obterem taxas de crescimento maiores. Nesse sentido, mesmo não ocorrendo inovações, é necessária mão de obra qualificada para que se possa empregar a tecnologia. $\mathrm{O}$ autor expôe também que a educação gera externalidades positivas sobre toda a economia, o que significa que o capital humano de um indivíduo particular contribui para melhorar o capital humano dos demais indivíduos à sua volta, contribuindo para a geração de capital social e para a melhoria das instituiçôes.

\section{1_Estudos empíricos e proxies de capital humano}

A partir dos modelos endógenos de crescimento econômico apontados na seção anterior, surge uma vasta gama de trabalhos empíricos, com os seguintes objetivos inter-relacionados: i) encontrar uma proxy para a variável estoque de capital humano; ii) verificar se o capital humano precede o crescimento econômico; e iii) identificar em que medida o capital humano colabora para o crescimento do produto.

Os primeiros trabalhos empíricos, nessa perspectiva, foram os modelos denominados Macro-Mincer, que aliam as duas áreas, isto é, estimam os retornos da educação de cunho micro, inserindo-os em modelos de crescimento macroeconômico e buscando mensurar os retornos da educação sobre o crescimento econômico, fazendo assim uma comparação entre países.

A grande discussão desses trabalhos se refere à proxy utilizada para o estoque de capital humano, que implicará diretamente nos resultados da variável dependente. As medidas que normalmente são encontradas nos trabalhos se referem a: i) número de alunos matriculados, ou porcentagem de concluintes, que está mais relacionado a variáveis de fluxo que a de estoque; ${ }^{8}$ e as variáveis
${ }^{8} \mathrm{Um}$ dos estudos que utiliza tal proxy é o de Mankiw et al. (1992). 
estoques como: ii) taxa de alfabetização ou nível educacional (anos de estudo); ${ }^{9}$. Esta última, em especial, há ainda a crítica sobre os pesos dados a cada ano adicional de estudo. ${ }^{10}$

Devido a esse detalhe metodológico na construção dos índices ou na especificação dos modelos, muitos trabalhos não encontram a relação positiva entre capital humano e crescimento. ${ }^{11}$ Influenciados por tal situação, Hall e Jones (1999) deram maior relevância para o aspecto da infraestrutura social, que está relacionada às condiçóes específicas dos países - como, por exemplo, a existência de instituiçóes fortes, que são determinadas historicamente - que criam e incentivam um ambiente favorável à geração de investimentos; nesse caso, os capitais humano e físico explicam parcialmente as diferenças de produtividade entre os países.
O estudo de Krueger e Lindahl (2001) traz uma nova interpretação sobre o impacto do capital humano sobre o crescimento. ${ }^{12}$ A conclusão a que chegaram foi que, para períodos curtos de tempo - até cinco anos -, a educação tem pouca ou nenhuma influência sobre o crescimento econômico. No entanto, para períodos maiores - de 10 a 20 anos - a influência é alta e significativa, um coeficiente em torno de 0,18 , apontando que é necessário um período mínimo para a educação exercer os efeitos de transbordamento (spillovers effects) sobre a economia.

Outra questáo levantada na pesquisa é que a maioria dos trabalhos empíricos - entre os quais se enquadram os dois trabalhos mencionados anteriormente - impóe a restrição de que todos os países têm a mesma relação entre crescimento e níveis iniciais de escolaridade, sendo essa relação linear. É devido a esse tipo de
${ }^{9}$ Há também a crítica sobre o grau de qualidade desse nível de escolaridade, que alguns estudos buscam mensurar utilizando os seguintes fatores: número de alunos por professor, escolaridade dos professores e aspectos relacionados à infraestrutura escolar, como existência e tamanho da biblioteca, número de computadores por aluno, etc.

${ }^{10}$ Esse tipo de proxy (média de escolaridade da populaçáo acima de 25 anos) é muito utilizado em trabalhos sobre convergência, e possui elevado poder de explicação das variaçóes nas taxas de crescimento entre os países, isto é, países com maior nível de educação crescem a taxas maiores que países com menor grau de escolaridade. Ver mais detalhes em Barro e Salai-Martin (1995). Para uma análise da construçáo da proxy de capital humano mencionada, ver Barro e Lee (1993).

\footnotetext{
${ }^{11}$ Um trabalho nesta linha é o de Benhabib e Spiegel (1994).

${ }^{12}$ Os autores partem da mesma proxy utilizada por Barro e Lee (1993), mas com a base de dados da World Values Survey (WVS) para 34 países, no período de 1960 a 1990.
} 
especificação que tais estudos não encontraram a relação positiva entre capital humano e crescimento econômico. Ao considerar uma relação não linear, a relação capital humano-PIB possui a forma de $\mathrm{U}$ invertido, com um pico de 7,5 anos de escolaridade, e a educação gera retornos positivos sobre o produto; mas, ao atingir um determinado nível de escolaridade, passa a crescer a taxas decrescentes no tempo. Essa relação implica que os efeitos da educação sobre o PIB serão diferentes para cada país, dependendo do nível de escolaridade que em cada um se encontra.

Ao considerar a relação não linear entre capital humano e crescimento pode-se explicar a divergência de resultados entre os trabalhos empíricos, pois em pesquisas que considerem amostras que contemplem a primeira fase de acumulação de capital humano, na qual há retornos crescentes, a relação será positiva; por outro lado, pesquisas que abranjam amostras maiores, e que contemplem toda a fase de acumulação, não encontrarão correlação, porque o efeito positivo é cancelado pelo efeito negativo.

Um estudo dessa linha é o de Dias e McDemortt (2003). Os autores evidenciam o efeito do valor barreira (threshold effect), que consiste no fato de que a acumulação de capital humano possui duas fases: na primeira, que varia de quatro a oito anos de estudo, a qualidade do capital humano não possui capacidade de gerar um processo cognitivo que implique maiores retornos sobre a produtividade, tendo pouco ou nenhum impacto sobre o produto; já no segundo estágio, após ultrapassar esse valor barreira, os retornos geram saltos, partindo para retornos crescentes de escala que implicam na melhora do processo cognitivo dos agentes econômicos, instituições e políticas econômicas, fatores responsáveis por explicar o crescimento sustentado no longo prazo. Sendo assim, percebe-se que deve haver um sacrifício inicial de crescimento econômico até se possibilitar a acumulação do capital humano mínimo necessário para gerar efeitos positivos sobre a economia. ${ }^{13}$

\section{2_ Proxy para estoque de capital humano dos municípios da região Sul do Brasil}

Buscando mensurar os efeitos do capital humano nos municípios da região Sul do país e contribuir com a literatura que aborda a temática, o presente estudo construiu uma variável para estoque de capital humano a partir do conceito de Mincer (1974), evidenciada na equação (2) a seguir, em que " $\theta$ " é o retorno associado a " $s$ " anos de escolaridade, e " $\gamma$ " e " $\delta$ " são os coeficientes referentes à idade e idade ao quadrado do indiví-
${ }^{13} \mathrm{O}$ valor barreira encontrado para níveis mundiais foi de 4,5 anos de escolaridade. Dias et al. (2005) encontram resultados semelhantes para o Brasil. 
${ }^{14}$ A pesquisa de Lam e Schoeni (1993) utiliza dados da PNAD de 1982 para homens casados na faixa etária de 30 a 55 anos, inserindo 17 dummies, uma para cada ano adicional de escolaridade.

${ }^{15}$ Veja em Beck et al. (2000) a exposição da ideia do autor. duo $i$, fatores que captam a experiência dos indivíduos.

$$
E H_{i}=\theta^{s i}+\gamma \operatorname{age}_{i}+\delta \operatorname{age}_{i}{ }_{i}
$$

Essa versão de estoque de capital humano é trabalhada por alguns autores, como Koman e Marin (1999), que calculam o estoque de capital humano para Áustria e Alemanha. Segundo os autores, nessa abordagem a produtividade dos trabalhadores é medida por sua remuneração no mercado de trabalho, e deixa-se de considerar que a produtividade cresce de forma proporcional com os anos de escolaridade, sendo ela assim mais apropriada para captar a heterogeneidade de conhecimento entre os indivíduos. Além disso, permite apontar uma relação não linear entre diferentes níveis de escolaridade e capital humano, apontando para o fato de que trabalhadores com diferentes níveis de conhecimento podem não ser substitutos perfeitos.

Para o cálculo da equação 2 , utilizam-se os coeficientes de " $\theta$ " estimados por Lam e Schoeni (1993).${ }^{14}$ Os coeficientes para idade " $\gamma$ " $\mathrm{e}$ " $\delta$ " foram extraídos do trabalho de Sachsida et al. (2004), em que ficaram em 0,068 e $-0,0008$, respectivamente, resultados muito próximos aos alcançados na literatura. Como insumo das variáveis anos de escolaridade e idade foram utilizados dados fornecidos pela RAIS (2006). Nesse aspecto, a RAIS permite que se extraia o número total de empregados em cada município, segmentado pelo seu grau de instrução e por sua idade.

Uma ressalva que é feita em relação aos coeficientes de retornos da educação utilizados é a de que esses coeficientes foram calculados para o Brasil, e, dada a existência de heterogeneidade entre as regiôes brasileiras, esse retorno pode causar algum viés nas estimativas. Porém, podese argumentar que essa heterogeneidade só se comprovará caso os coeficientes do capital humano estimados não sejam estatisticamente significantes.

Outra ressalva a ser feita diz respeito à base de dados utilizada - RAIS -, uma vez que ela contempla apenas informaçóes do mercado formal. A escolha da RAIS se deve à amplitude que ela oferece em nível municipal e à confiança de suas informaçóes, contemplando estatísticas do mercado de trabalho formal da totalidade de municípios brasileiros.

\section{4_ O sistema financeiro e o crédito}

A discussáo sobre a capacidade de o sistema financeiro influenciar a atividade econômica é antiga, e pode ser remontada à opinião de Schumpeter (1911), ${ }^{15}$ 
que sustenta que os bancos favorecem a inovação tecnológica por alocarem poupança em novos empreendimentos. Essa visão, porém, ganhou maior destaque a partir da década de 1980, com o advento da teoria de assimetria de informaçóes, com Stiglitz e Weiss ( ) enfatizando, em seu artigo, como este problema pode gerar racionamento de crédito.

As pesquisas sobre assimetria de informaçóes possibilitaram ampliar a análise da influência do setor bancário sobre a atividade econômica. Essas pesquisas impuseram um novo prisma sobre os efeitos da política monetária tradicional, pois se verificou que a taxa de juros dos títulos federais (Selic) afeta os investimentos de forma indireta, enquanto a influência direta vem da taxa de juros cobrada pelos bancos (spread). Dessa forma, o consenso de que a política monetária afeta variáveis reais no curto prazo induziu a mensuração desse curto prazo, no qual perduram os efeitos sobre a economia, e da maneira pela qual esses efeitos se propagam após o choque, propagação também conhecida como mecanismo de transmissão monetária. ${ }^{16}$

Um trabalho seminal nessa área é o de Blinder e Stiglitz (1983), que sustenta que dada a aversão ao risco pelos bancos, estes tomarão uma posição defensiva num ambiente de política monetária restritiva, reduzindo a oferta de crédito e canalizan- do-a para empresas com melhor situação financeira (fly to quality). Essa redução nas operaçōes de crédito pode gerar uma contração no nível de investimentos, resultando numa ampliação dos efeitos recessivos da política monetária.

\section{1_A contribuição do sistema financeiro para o crescimento econômico}

Conforme explorado na seção anterior, o advento da teoria de assimetria de informações e a comprovação de muitos estudos sobre os canais de crédito deram maior sustentação para se explorar a influência do sistema financeiro sobre o crescimento econômico dos países. Essa tese é sustentada por Levine (1997) ao apresentar a função do sistema financeiro na economia: mobilizar poupança com os menores custos de informação e transação, tendo expertise para reduzir os riscos em selecionar e monitorar os melhores negócios, financiando investimentos, inovação e acumulação de capital humano.

Um dos trabalhos que exploraram o componente exógeno de desenvolvimento do sistema financeiro foi realizado por King e Levine (1993). A conclusão dos autores foi a de que, se os países em desenvolvimento tivessem adotado o mesmo grau de intermediação financeira dos países desenvolvidos, teriam obtido crescimento adicional de $1 \%$ a.a.

\footnotetext{
${ }^{16}$ Para maiores detalhes sobre os mecanismos de transmissão monetária ver Mishkin (1996). Um desses mecanismos, muito discutido a partir da década de 1980, é o canal de crédito, conforme Bernanke e Blinder (1988) e Bernanke e Gertler (1995). Trabalhos empíricos sobre canais de crédito remetem a Gertler e Gilchrist (1994) para os EUA, Favero, Giavazzi e Flabbi (1999) para a Europa, e Sobrinho (2003) para o Brasil..
} 


\footnotetext{
${ }_{17}$ Conforme segmentação apontada pelo COSIF

(Plano Contábil das

Instituiçôes Financeiras do Sistema Financeiro Nacional do BACEN), em que crédito para investimento se refere às operaçôes realizadas com destinação específica, vinculadas à comprovação da aplicação dos recursos. São exemplos os financiamentos de parques industriais, máquinas e equipamentos, e de bens de consumo durável (rurais e imobiliários).
}

no seu PIB. Outros trabalhos que também encontraram uma relaçáo positiva do sistema financeiro sobre o produto foram os de Levine (1997) e Rajan e Zingales (1998). A pesquisa de Levine et al. (1999) adotou uma nova metodologia econométrica para tratar do tema (método de GMM em painéis de dados). O resultado de destaque foi que os 10 países que mais cresceram no período tiveram a relação operações de crédito/PIB acima da média.

Para o Brasil há poucos trabalhos empíricos na área, pois a maioria dos estudos voltados ao sistema financeiro se preocupa em encontrar a existência dos canais de crédito. Somente a partir dos anos 2000 novos trabalhos têm buscado captar as variáveis promotoras do crescimento econômico, e emerge desse contexto o interesse em investigar as relaçóes do sistema financeiro sobre o produto. Neste rol encontram-se os trabalhos de Matos (2002), de Alexandre, Biderman e Lima (2004) e de Dias e Araújo (2005).

Após essa incursão sobre as principais teorias que englobam as variáveis capital humano e crédito explicando o crescimento econômico, apresenta-se, na próxima seção, a metodologia econométrica utilizada, a base de dados e os resultados das estimativas deste trabalho.

\section{Estudo econométrico em dados de painel}

A base de dados a ser trabalhada compreende 747 municípios da região Sul do Brasil, sendo considerados na amostra apenas os municípios que tiveram informaçôes disponíveis para todas as variáveis a serem utilizadas nas regressóes, uma vez que se pretende trabalhar com painéis balanceados, isto é, painéis que possuam todas as observaçóes de todas as variáveis no tempo. O período a ser analisado é o de 1999 a 2004.

Dos 747 municípios, 293 pertencem ao estado do Paraná, 202 a Santa Catarina e 252 ao Rio Grande do Sul, resultando num total de 4.482 observaçóes para cada variável utilizada. Essa parcela de municípios representa cerca de $60 \%$ do total de municípios da região. $\mathrm{O}$ pequeno período da análise deve-se ao fato de esse conjunto ser o único disponível no momento, de forma completa, para os nossos propósitos.

A Tabela 1 apresenta as variáveis utilizadas na pesquisa, que foram obtidas junto ao IBGE (PIB municipal e população, 2005), ao BACEN (operações de crédito para investimento, ${ }^{17} 2005$ ), ao Tesouro Nacional (gastos em capital pelo governo municipal e transferências de capital dos Estados e da União, 2006) e ao MTE/RAIS (número de funcionários e grau de instrução, 2006). 
Todas as variáveis foram linearizadas, o que permite analisar os parâmetros em termos percentuais, além de possibilitar a correção de problemas de normalidade devido à presença de outliers, como é o caso de grandes municípios. As variáveis monetárias foram deflacionadas pelo IGP-M para o ano de 1999.

Apesar de ser simples a leitura das variáveis apresentadas na Tabela 1 , para maior compreensão a partir dela será realizada a inferência da variável PIB municipal. Nesse sentido, o PIB dos municípios da região Sul apresentou uma média de R 216 milhóes, sendo o menor de R\$ 7,58 milhóes e o maior de $\mathrm{R} \$ 12.400 \mathrm{mi}$ lhôes, apresentando um desvio padrão de R 683 milhóes.

Através da base de dados foi possível calcular os seguintes indicadores, que serão os utilizados no trabalho:

_ Produto municipal per capita, calculado pela divisáo do PIB municipal pela população do município (yln);

_ Proxy de estoque de capital humano dos municípios, calculada conforme especificação no item 3.2, da seção 3 (khumano);
_ Proxy de investimento privado em capital físico, representado pelo valor do crédito bancário para investimento per capita, obtido pela divisão do valor das operaçóes de crédito para investimento pela população (opcredito); ${ }^{18}$

_ Investimento em capital pelo governo municipal per capita, resultado da despesa das prefeituras em capital físico dividido pela população (investmunk);

_ Transferência de capital dos governos estadual e federal para os municípios; essa variável também foi dividida pela população (transf_fedest_k).

\section{1_Metodologia Econométrica}

Dados de painéis são a junção de dados de corte e de série temporal, e segundo Baltagi (2005) possuem alguns benefícios, como ganho de graus de liberdade, melhor tratamento de variáveis microeconômicas, possibilidade de controle da heterogeneidade individual, além de serem um modelo mais adequado para estudos dinâmicos.
${ }^{18}$ Uma proxy geralmente utilizada para capital físico se refere ao consumo de energia elétrica e/ou ao estoque de capital físico nos municípios, embora em nível municipal essas variáveis nem sempre estejam disponíveis. 
Tabela 1 Sumário da base de dados - 1999-2004

\begin{tabular}{|c|c|c|c|c|c|c|}
\hline Variável & & Média & Desvio Padrão & Mínimo & Máximo & Observações \\
\hline \multirow[t]{3}{*}{ PIB Municipal } & Total & $2.16 \mathrm{e}+08$ & $6.83 \mathrm{e}+08$ & 7.578 .309 & $1.24 \mathrm{e}+10$ & $\mathrm{~N}=4482$ \\
\hline & Entre & & $6.79 \mathrm{e}+08$ & 9.214 .962 & $1.07 \mathrm{e}+10$ & $\mathrm{n}=747$ \\
\hline & Dentro & & $7.60 \mathrm{e}+07$ & $-1.30 \mathrm{e}+09$ & $1.91 \mathrm{e}+09$ & $T=6$ \\
\hline \multirow[t]{3}{*}{ Op. Crédito Invest. } & Total & $2.09 \mathrm{e}+07$ & $1.82 \mathrm{e}+08$ & 1 & $5.18 \mathrm{e}+09$ & $N=4482$ \\
\hline & Entre & & $1.76 \mathrm{e}+08$ & 8.278 .333 & 3.89 e +09 & $\mathrm{n}=747$ \\
\hline & Dentro & & $4.72 \mathrm{e}+07$ & $-8.63 e+08$ & $1.48 \mathrm{e}+09$ & $T=6$ \\
\hline \multirow[t]{3}{*}{ Invest. Púb. Municipal } & Total & 1.397 .634 & 4.888 .226 & 0 & $1.12 \mathrm{e}+08$ & $N=4482$ \\
\hline & Entre & & 4.661 .735 & 49.461 & 8.78 e +07 & $\mathrm{n}=747$ \\
\hline & Dentro & & 1.478 .926 & $-2.13 e+07$ & $4.45 \mathrm{e}+07$ & $T=6$ \\
\hline \multirow[t]{3}{*}{ Invest. Púb. Est/Fed } & Total & 196.619 & 556.472 & 0 & $1.35 \mathrm{e}+07$ & $\mathrm{~N}=4482$ \\
\hline & Entre & & 429.427 & 0 & 6.564 .111 & $\mathrm{n}=747$ \\
\hline & Dentro & & 354.203 & -4.823 .573 & 7.582 .687 & $\mathrm{~T}=6$ \\
\hline \multirow[t]{3}{*}{ Capital Humano } & Total & 101.071 & 610.616 & 455 & $1.29 \mathrm{e}+07$ & $\mathrm{~N}=4482$ \\
\hline & Entre & & 608.591 & 1.599 & $1.12 \mathrm{e}+07$ & $\mathrm{n}=747$ \\
\hline & Dentro & & 53.689 & -1.237 .409 & 2.019 .612 & $T=6$ \\
\hline \multirow[t]{3}{*}{ População } & Total & 32.130 & 92.834 & 1.865 & 1.727 .010 & $\mathrm{~N}=4482$ \\
\hline & Entre & & 92.835 & 2.019 .667 & 1.656 .038 & $\mathrm{n}=747$ \\
\hline & Dentro & & 3.073 .123 & -28.875 & 103.102 & $T=6$ \\
\hline \multirow[t]{3}{*}{ Empregados } & Total & 6.437 .311 & 31.703 & 34 & 633.869 & $N=4482$ \\
\hline & Entre & & 31.675 & 1.096 .667 & 581.042 & $\mathrm{n}=747$ \\
\hline & Dentro & & 1.691 .337 & -32.640 & 59.264 & $\mathrm{~T}=6$ \\
\hline
\end{tabular}

Fonte: Elaboraçấo própria, a partir de dados do BACEN (2005), IBGE (2006), RAIS/MTE (2005), TESOURO NACIONAL (2006). 
Os modelos para estimar painéis são variantes de Mínimos Quadrados Ordinários (MQO), mas se diferenciam quanto à natureza do erro. $\mathrm{O}$ modelo tradicional de painéis segue o padrão dado na equação 3 , em que $Y_{i t}$ representa a variável dependente (produto municipal per capita i no tempo t na forma logarítmica, por exemplo); $\beta$ são os parâmetros a serem estimados (vetor $\mathrm{kx} 1$ ); e $\epsilon_{i t}$, são as variáveis independentes (vetor $\mathrm{kx} 1$ ). Se o painel possuir $\mathrm{k}$ variáveis explicativas, então $\mathrm{j}=1, \ldots, \mathrm{k}$, (por exemplo, crédito para investimento, estoque de capital humano e investimento público em capital). Por último, $\epsilon_{i t}$ é a medida de erro.

$$
Y_{i t}=\beta^{\prime} X^{j}{ }_{i t}+\epsilon_{i t} \text {, em que } \epsilon_{i t}=\alpha_{i}+\eta_{i t}
$$

O erro é dividido em duas partes: a primeira $\left(\alpha_{i}\right)$ é chamada de efeito fixo do município ou efeito individual, e se refere ao erro de corte transversal; . a segunda $\left(\eta_{i t}\right.$ ) é o elemento de erro combinado da série temporal e do corte transversal (variando através dos municípios e do tempo, sendo o erro convencional das regressóes), e assume-se que não está correlacionado com as variáveis explicativas $\left(X_{i t}^{j}\right)$.

O efeito individual, não observável, capta elementos importantes de forma indireta como, por exemplo, clima, relevo e colonização dos municípios. $\mathrm{O}$ segundo elemento do erro na equação (3) varia não sistematicamente, e de forma independente, ao longo do tempo e dos municípios. Essa conotação quanto aos efeitos individuais dos municípios permite testar qual é o modelo mais apropriado para se explicar o comportamento: efeitos fixos ou efeitos aleatórios. ${ }^{19}$

A diferença entre eles consiste em o efeito estar ou não correlacionado com as variáveis explicativas. Nos efeitos aleatórios, o efeito do indivíduo não está correlacionado com as variáveis independentes e náo muda ao longo do tempo, $\mathrm{E}\left(X_{i t}, \alpha_{i}\right)=0$. Já para os efeitos fixos, o efeito do indivíduo está correlacionado, $\mathrm{E}\left(X_{i t}, \alpha_{i}\right) \neq 0$, o que quer dizer que condiçóes preexistentes nos municípios estão presentes em $X_{i t}$.

Para trabalhar um painel dinâmico realiza-se uma modificação na equação 3, na qual é inserida uma variável dependente defasada entre os regressores, instrumentalizando a equação, que fica da seguinte forma:

$$
\begin{aligned}
& y_{i t}=\delta y_{i, t-1}+X^{\prime}{ }_{i t} \beta+\epsilon_{i t} \text { em que } \\
& \epsilon_{i t}=\alpha_{i}+\eta_{i t}
\end{aligned}
$$

O erro nesse modelo segue estrutura anterior, e o maior problema que

\footnotetext{
${ }^{19} \mathrm{Um}$ dos testes realizados para verificar a presença destes efeitos é o de Hausman (1978).
} 


\footnotetext{
${ }^{20}$ A utilização deste método é testada em Blundell e Bond (1998b).

${ }^{21}$ Conforme Hsiao (2003), este sistema GMM liga dois modelos dinâmicos em painéis; o primeiro utiliza a metodologia de Arellano e Bond (1991), com defasagens como instrumentos, e o segundo é uma extensão da versão de Arellano e Bover (1995), utilizando defasagens como instrumentos em equaçóes de níveis.
}

surge com a equação 4 é a possibilidade de que $Y_{\mathrm{i}, \mathrm{t}-\mathrm{i}}$ esteja correlacionado com os erros, viesando os resultados das estimativas dos parâmetros. Outro problema é que as variáveis independentes podem não ser exógenas, significando que essas variaçôes são correlacionadas com variações futuras da variável dependente, o que gera a situação de causalidade reversa.

Para estimar o modelo dinâmico, conforme mencionado anteriormente, recorremos à GMM proposta por Blundell e Bond (1998a). Segundo os autores, os resultados podem ser bem melhores (maior consistência e eficiência) se incorporarem mais condiçóes de momentos. Assim este modelo faz o uso de defasagens em diferenças como instrumentos em equaçóes de níveis e em nível para as equaçóes em primeira-diferenças. ${ }^{20}$ Essa conotação rende um sistema GMM de equações simultâneas, contendo ambas as equaçóes, em primeira-diferença e em nível. ${ }^{21}$

Ainda segundo Baltagi (2005), a consistência dos instrumentos GMM depende da validade das seguintes hipóteses: i) que o termo de erro $\left(\epsilon_{i t}\right)$ não possua correlaçáo serial, e ii) que os instrumentos sejam válidos. Para testar essas hipóteses utilizam-se dois testes. $\mathrm{O}$ primeiro, de autocorrelação de primeira e segunda ordem, em que os parâmetros são eficien- tes mesmo sob autocorrelação de primeira ordem, mas não para a de segunda ordem. Já para se testar a validade dos instrumentos, faz-se um teste de over-identificação dos instrumentos. Esse teste foi proposto por Hansen, e a hipótese nula de validade dos instrumentos desse teste segue distribuição $\chi^{2}$ com $(\mathrm{J}-\mathrm{K})$ graus de liberdade, em que J é o número de instrumentos e $\mathrm{K}$ é o número de regressores.

\section{2_ Testes e resultados}

Nos testes de especificação do modelo se comparam os modelos estimados sob efeitos fixos e variáveis, isto é, verifica-se se os efeitos individuais estão correlacionados ou não com as variáveis independentes, para dessa forma escolher o estimador mais apropriado para a regressão, se o de efeitos fixos ou o de aleatórios. A tabela 2 apresenta os resultados das regressóes para os modelos de efeitos fixo e aleatório.

Os resultados, tanto para efeitos fixos como para efeitos aleatórios, indicam baixo poder de explicação, além da variável investimento público em capital pelo município (investmunk) não ser significante. Essa situação pode ser gerada devido à existência de autocorrelação e de heterocedasticidade, os quais deverão ser corrigidos.

A identificação de qual modelo se ajusta melhor ao nosso problema po- 
Tabela 2: Resultado das regressões realizadas para os efeitos fixo e aleatório, explicando o PIB per capita municipal (yln)

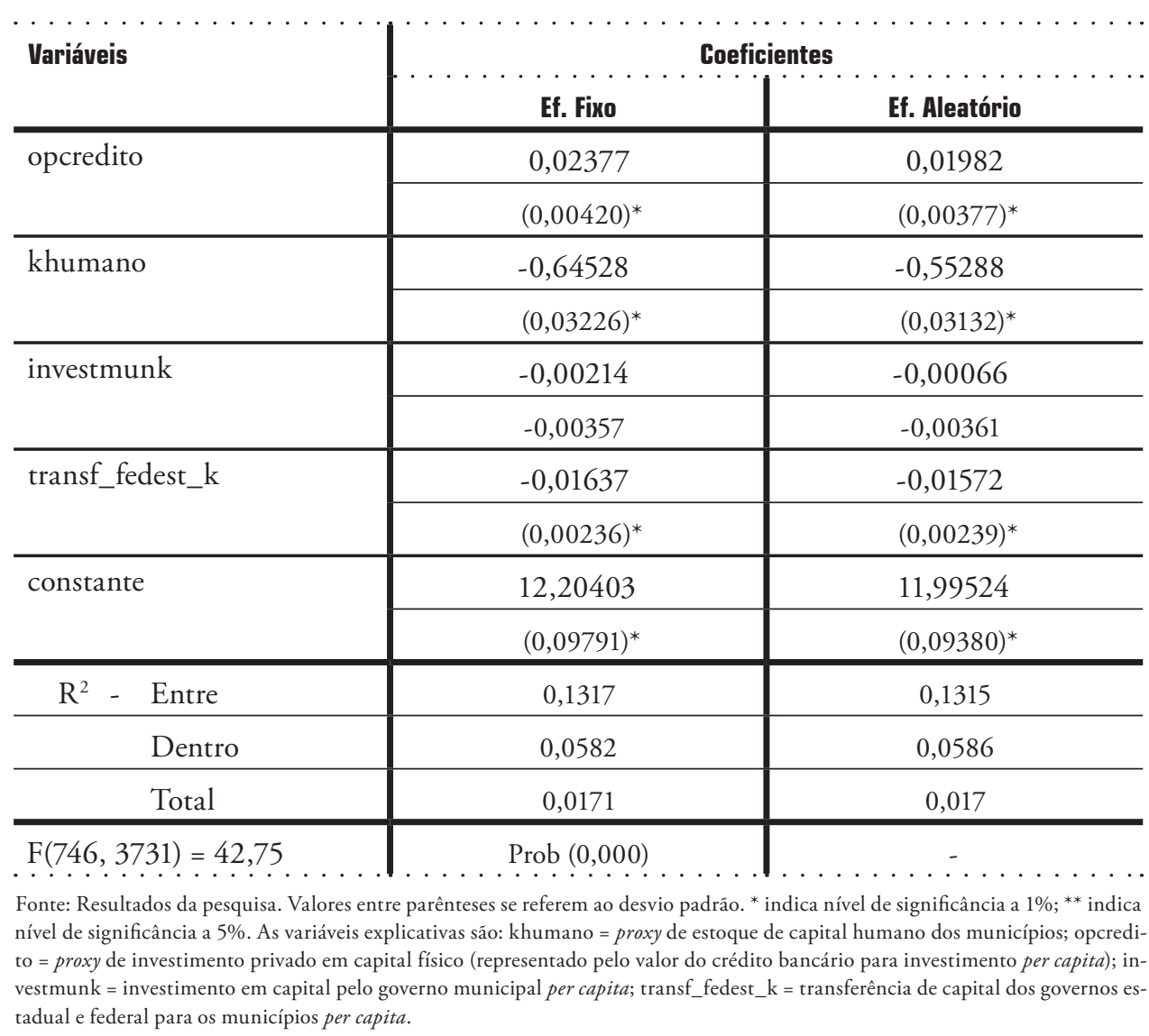

de ser obtida com a aplicaçáo do teste de especificação de Hausman (1978). O resultado encontrado demonstra a elevada probabilidade de que os coeficientes sejam sistemáticos, ou seja, eles relacio- nam-se aos efeitos fixos. Nesse sentido, o valor do teste $\chi^{2}=278,95$ rejeita a hipótese nula, sendo que Prob $>\chi^{2}=0,000$, confirmando assim o modelo de efeitos fixos como o mais adequado. 
${ }^{22}$ Foram realizados também os testes de Wald Modificado, para heterocedasticidade, $\mathrm{e}$ o teste de autocorrelaçáo proposto por Wooldridge (2002) apud Baltagi (2005), que confirmam a existência desses problemas..
Além do teste de Hausman, foram realizados ainda outros testes que visam identificar a presença de efeitos aleatórios. Os testes realizados referem-se aos de Máxima Verossimilhança (MV), proposto por Breusch e Pagan (1980) apud Hsiao (2003) e por Baltagi-Li (1995) apud Hsiao (2003), considerando a autocorrelação, e ao teste de Baltagi-Li (1991) apud Hsiao (2003), que testa conjuntamente a autocorrelação e a heterocedasticidade. Os resultados de todos os testes apontam para a rejeição do modelo de efeitos aleatórios, ou seja, a probabilidade de existência do efeito aleatório é zero. ${ }^{22}$

Levando em consideração os resultados dos testes realizados, em que se evidenciou a existência de efeitos fixos e dos problemas de autocorrelação e heterocedasticidade, analisam-se agora as regressões que visam explicar as contribuições dos capitais físicos e humano sobre o produto per capita dos municípios. Como primeiro exercício, realizaram-se três regressões de painéis estáticos, e os resultados estão expostos na Tabela 3.

A primeira regressão realizada, coluna (1), admite como hipótese a existência de exogeneidade contemporânea das variáveis independentes. A exogeneidade admitida decorre da possibilidade de existência de causalidade reversa entre as variáveis inseridas no modelo, co- mo o crescimento do produto per capita interferindo na ampliação do crédito para investimentos pelos bancos.

Essa regressão foi realizada através do método de Prais-Winsten, que corrige os painéis dos problemas de autocorrelação e de heterocedasticidade. Esse método utiliza duas correçóes para o problema: uma se vale de um coeficiente comum para todas as observaçóes e outra corrige cada painel pelo seu respectivo coeficiente de correlação serial.

Os resultados dessa regressão, coluna (1), demonstram a significância das variáveis independentes, explicando o produto municipal per capita. Nesse sentido, o crédito para investimento contribui em $0,105 \%$ para o aumento do produto per capita, em decorrência de uma elevação em $10 \%$ desse tipo de crédito. $\mathrm{O}$ capital humano, por sua vez, gera um retorno ainda maior: para cada $10 \%$ de incremento nessa variável, a produtividade eleva-se em 3,21\%. Para as variáveis investmunk e transf_ fedest_k, o primeiro contribui positivamente, com um coeficiente de 0,035, e o segundo negativamente, com $-0,021$.

A coluna (2) da Tabela 3 apresenta os resultados da regressão de painel estático, também utilizando o método de Prais-Winsten, mas agora inserindo uma defasagem da variável dependente nas 
Tabela 3: Regressão de painéis estáticos explicando produto per capita municipal

\begin{tabular}{|c|c|c|c|}
\hline Variáveis & [1] & $\begin{array}{c}\text { Coeficientes } \\
\text { [2] }\end{array}$ & [3] \\
\hline \multirow[t]{2}{*}{ opcredito } & 0,01047 & & 0,08198 \\
\hline & $(0,00339)^{*}$ & & $(0,00902)^{*}$ \\
\hline \multirow[t]{2}{*}{ l.opcred } & & 0,01274 & \\
\hline & & $(0,00384)^{*}$ & \\
\hline \multirow[t]{2}{*}{ khumano } & 0,32115 & & 0,43111 \\
\hline & $(0,01422)^{*}$ & & $(0,03134)^{*}$ \\
\hline \multirow[t]{2}{*}{ 1.lkhumedio } & & 0,31023 & \\
\hline & & $(0,01659)^{*}$ & \\
\hline \multirow[t]{2}{*}{ investmunk } & 0,03484 & & 0,03067 \\
\hline & $(0,00638)^{*}$ & & $(0,01019)^{*}$ \\
\hline \multirow[t]{2}{*}{ 1.linvestmunpc } & & 0,0684 & \\
\hline & & $(0,00757)^{*}$ & \\
\hline \multirow[t]{2}{*}{ transf_fedest_k } & $-0,02096$ & & $-0,03106$ \\
\hline & $(0,00305)^{*}$ & & $(0,00495)^{*}$ \\
\hline \multirow[t]{2}{*}{ 1.ltransfkpc } & & 0,00152 & \\
\hline & & $-0,00325$ & \\
\hline \multirow[t]{2}{*}{ constante } & 8,30942 & 8,16053 & 8,00991 \\
\hline & $(0,02818)^{*}$ & $(0,03341)^{*}$ & $(0,04910)^{*}$ \\
\hline Wald $($ chi 2$)=683,67$ & 0 & & \\
\hline Wald $($ chi 2$)=536,90$ & & 0 & \\
\hline$F(4,1942)=88,49$ & & & 0 \\
\hline $\mathrm{R} 2$ & 0,9808 & 0,9822 & 0,1966 \\
\hline \multicolumn{4}{|c|}{$\begin{array}{l}\text { Fonte: Resultados da pesquisa. Valores entre parênteses se referem ao desvio padrão. }{ }^{*} \text { indica nível de significância a } 1 \% \text {; }{ }^{*} \text { indica } \\
\text { nível de significância a } 5 \% \text {. As variáveis explicativas săo: khumano = proxy de estoque de capital humano dos municípios; opcredi- } \\
\text { to = proxy de investimento privado em capital físico (representado pelo valor do crédito bancário para investimento per capita); in- } \\
\text { vestmunk = investimento em capital pelo governo municipal per capita } \text {; transf_fedest_k }=\text { transferência de capital dos governos es- } \\
\text { tadual e federal para os municípios per capita. }\end{array}$} \\
\hline
\end{tabular}


variáveis explicativas. Essa inclusão da defasagem da variável explicativa reduz os efeitos de auto regressividade, uma vez que considera os efeitos passados sobre a dependente. Mesmo realizando a defasagem, as variáveis continuam demonstrando resultados próximos ao do exercício anterior, com alta significância, bem como R2 elevado, de 98,22\%. A única variável que não apresentou significância foi a das transferências federais de capital para os municípios - transf_fedest_k -, o que confirma o coeficiente encontrado na regressão anterior.

$\mathrm{Na}$ terceira regressão, coluna (3), considera-se a presença dos efeitos fixos, e a forma de estimação utilizada busca eliminar sua influência sobre os resultados, no intuito de extrair a participação isolada/líquida das variáveis explicativas. Considerando esses efeitos, os coeficientes gerados apresentam significância elevada (em nível de 1\%). As variáveis operaçôes de crédito e capital humano aumentam sua participação em relação às regressóes realizadas anteriormente, isto é, as operaçóes de crédito contribuem para a melhoria da produtividade em $0,82 \%$, para um incremento de $10 \%$ nos empréstimos bancários para investimento. Para o capital humano, o índice de 0,431 indica que o estoque de conhecimento na econo- mia contribui em 4,31\%, conforme incremento de $10 \%$ nessa variável.

\section{3_Estimação dinâmica}

Como último exercício, e após apresentar as regressóes estáticas em painéis, realiza-se a regressão de forma dinâmica, com o objetivo de retirar qualquer influência contemporânea das variáveis explicativas, além de isolar os efeitos fixos. Para a realização da estimativa dinâmica dos painéis, utilizaram-se como instrumentos GMM as variáveis PIB municipal per capita, capital humano, investimento municipal e transferência dos governos estadual e federal em capital com quatro defasagens.

A regressão na forma dinâmica possibilita eliminar a interferência dos efeitos fixos dos municípios, indicando dessa forma a total exogeneidade das variáveis e seu efeito líquido sobre a variável dependente, efeito esse que não depende das condiçóes iniciais do município. Assim, o modelo considera a autocorrelação de primeiro grau, mas ignora a autocorrelação de segundo grau. Os coeficientes gerados são altamente significativos, com exceção da variável crédito para investimento. Os resultados estão expostos na Tabela 4.

Uma possível explicação para a não significância do crédito para inves- 
Tabela 4: Resultado da regressão dinâmica, explicando produto municipal per capita

\begin{tabular}{|c|c|}
\hline Variável & Coeficiente \\
\hline \multirow[t]{2}{*}{ pibmunicipal (L1) } & 0,46068 \\
\hline & $(0.10129)^{*}$ \\
\hline \multirow[t]{2}{*}{ opcredito (L1) } & $-0,03293$ \\
\hline & $(0.09151)$ \\
\hline \multirow[t]{2}{*}{ khumano (L1) } & 0,19261 \\
\hline & $(0.11530)^{* * *}$ \\
\hline \multirow[t]{2}{*}{ investmunk (L1) } & 0,20877 \\
\hline & $(0.06810)^{*}$ \\
\hline \multirow[t]{2}{*}{ transf_fedest_k (L1) } & 0,0499 \\
\hline & $(0,02157)^{* *}$ \\
\hline \multirow[t]{2}{*}{ constante (L1) } & 3,84937 \\
\hline & $(1,28276)^{*}$ \\
\hline Teste de Hansen chi2(3)=3,10 & Prob $>$ chi $2=0.376$ \\
\hline Teste Arellano-Bond AR(1) & $\operatorname{Pr}>z=0.002$ \\
\hline Teste Arellano-Bond AR(2) & $\operatorname{Pr}>z=0,804$ \\
\hline \multicolumn{2}{|c|}{$\begin{array}{l}\text { Fonte: Resultados da pesquisa. Valores entre parênteses se referem ao desvio padrăo, }{ }^{*} \text { indica nível de significância a } 1 \% \text {; }{ }^{* *} \text { indi- } \\
\text { ca nível de significância a } 5 \% \text {; } * * \text { indica nível de significância a } 10 \% \text {. As variáveis explicativas são: khumano = proxy de estoque } \\
\text { de capital humano dos municípios; opcredito = proxy de investimento privado em capital físico (representado pelo valor do crédito } \\
\text { bancário para investimento per capita); investmunk = investimento em capital pelo governo municipal per capita; transf_fedest_k } \mathrm{k} \text { - } \\
=\text { transferência de capital dos governos estadual e federal para os municípios per capita. }\end{array}$} \\
\hline
\end{tabular}

timento na análise dinâmica deve-se, primeiramente, à baixa relação crédito/PIB existente na região Sul. No caso do Brasil, o país possui uma das mais baixas participaçóes de operaçóes sobre o PIB, se comparado com outros países em desenvolvimento. Essa relação apresentou queda no período de análise, passando de 30\%, em 1999, para 23\%, em 2004. A regiáo Sul apresentou o mesmo movimento: o Rio Grande do Sul observa uma queda de $23 \%$ para $21 \%$; em Santa Catarina, a relação passa de $16 \%$ para $13 \%$; e, no Paraná, de $24 \%$ para $19 \%$. 
Essa baixa relação pode indicar a não influência dos canais de crédito sobre a transmissão da política monetária nos municípios da regiấo Sul, uma vez que, no período de análise, 1999 a 2004, o país conviveu com uma política monetária contracionista, em virtude da manutenção da política anti-inflacionária do Plano Real, inibindo a oferta de crédito por parte dos bancos.

Outra explicação para a não significância do crédito para investimento pode ser o baixo período da análise (seis anos), pois geralmente este tipo de crédito possui um prazo maior de maturação, como construção de galpóes industriais, aquisição de máquinas e equipamentos, implantação de sistemas, e nesse sentido os reflexos sobre a economia não são imediatos.

Para o capital humano, o coeficiente de 0,193 é menor, se comparado aos coeficientes obtidos nas outras regressóes, mas é significativo e elevado. Esse resultado é muito próximo dos coeficientes encontrados em outros estudos empíricos que tratam de verificar sua importância sobre o produto. Os exemplos clássicos são o de Lau et al. (1993), que encontrou um coeficiente de 0,20 , analisando dados de 1970 e 1980 para os estados brasileiros; e de Cangussu, Salvato e Nakabashi (2010), no qual o coeficiente se situou em torno de 0,15 (retorno de um ano adicional de escolaridade, de acordo com especificação de Mincer, 1974), também realizando análise para os estados brasileiros, mas para o período de 1980 a 2002. Ressalta-se que a técnica econométrica utilizada nesse último trabalho também foi a de painéis de dados dinâmicos.

Ao comparar os coeficientes encontrados para o capital humano no presente estudo com os demais citados verifica-se que os municípios da região Sul não diferem da média nacional. Essa evidência contrasta com a heterogeneidade da média de escolaridade verificada no país, em que a regiẫo Sul se sobressai. Uma explicação plausível pode ser relacionada à teoria do efeito do valor barreira (threshold effect), em que os municípios da região Sul estariam localizados no ponto crítico da primeira fase de acumulação de conhecimento, necessitando dar um salto (que pode ser referido à qualidade da educação) para ultrapassar o valor barreira e ter a possibilidade de atingir maiores níveis de retorno do capital humano sobre o produto.

As variáveis que tratam do investimento público em capital, como os investimentos pelas prefeituras com recursos próprios e com as transferências dos governos federal e estadual, apresentaram-se positivas e significativas, alcançando coe- 
ficientes de 0,05 e 0,209 , respectivamente. A variável transf_fedest_k passa a ser significativa no modelo dinâmico. Uma explicação para o fato pode ser o fato de que, no longo prazo, esses gastos são complementados com os gastos municipais em infraestrutura, causando impactos positivos sobre o produto, ou, ain$\mathrm{da}$, de que alguns investimentos, como a construção de escolas, passam a gerar retornos somente no longo prazo.

Já os investimentos municipais, investmunk, apresentaram um coeficiente bem superior àquele verificado para transf_fedest_k. Esse valor pode estar sendo influenciado pelo fato de que os investimentos em capitais pelos governos municipais são mais produtivos do que aqueles advindos daquelas esferas. Mas também capta o baixo nível de investimentos estaduais e federais nos últimos anos. Esse baixo nível de participação forçou os municípios a iniciarem projetos próprios para gerar um ambiente propício para a atração de investimentos externos a eles.

Há que se considerar, ainda, o valor da constante, que se reduziu significativamente se comparado com as outras regressóes, demonstrando que as variáveis independentes utilizadas explicam bem as variaçóes da produtividade no tempo e entre os municípios. A validade desses resultados é confirmada pelos testes de Hansen, que apontam a probabilidade de os instrumentos serem ortogonais em $38 \%$, e pelo teste de autocorrelação de Arellano-Bond, apontando para a probabilidade de $80 \%$ para a não ocorrência de autocorrelação de segunda ordem.

\section{6_Considerações finais}

O presente estudo procurou demonstrar a contribuição dos capitais físico e humano para o aumento do crescimento do produto municipal per capita dos municípios da regiấo Sul do Brasil. A variável capital físico foi dividida em público e privado, sendo o capital público representado pelos gastos em capital pelos governos municipal, estadual e federal. Para o capital privado, foi utilizado o volume de crédito bancário para investimento, considerando assim o papel do sistema financeiro em alocar a poupança para novos empreendimentos produtivos na economia. Quanto ao capital humano, foi construído o estoque de conhecimento nos municípios seguindo a metodologia proposta por Koman e Marin (1999), tendo como insumo a base de dados da RAIS.

$\mathrm{O}$ estudo econométrico em dados de painéis dinâmicos, conforme metodologia de Blundell e Bond (1998a), 
encontrou como resultado o efeito causal positivo das variáveis capital humano, com coeficiente de 0,19 ; investimento público, tanto pelos governos municipais como pelas outras esferas, com 0,21 e 0,05 , respectivamente; e do produto municipal per capita defasado, com coeficiente de 0,46.

A variável construída do setor bancário que capta o crédito para investimento, por sua vez, não alcançou significância, o que pode evidenciar pelo menos duas situaçóes: i) baixo volume desse tipo de crédito por parte dos bancos, representado pela baixa relação crédito/PIB no país, se comparado com outros países. Essa baixa relação indica ainda que a maior parcela dos investimentos privados é realizada com recursos próprios e/ou lucros reinvestidos, confirmando a existência de restrições de crédito por parte dos bancos e a não presença dos canais de crédito nos municípios; e ii) prazo estendido de maturação desses créditos na economia, uma vez que se referem a créditos de longo prazo. Em suma, os créditos bancários para investimento nos municípios são escassos, e num volume abaixo do necessário para gerar efeitos positivos sobre o crescimento municipal.

Os coeficientes de capital humano (próximos aos coeficientes encontra- dos nos demais trabalhos da área) e seu efeito causal evidenciam que: i) o elevado valor do coeficiente demonstra o forte efeito spillover da educação sobre o produto dos municípios, indicando ser uma política pública a ser aprimorada e perseguida pelas esferas governamentais; ii) o impacto do capital humano nos municípios da região Sul só não é maior em virtude de estarem situados no ponto ótimo da primeira fase de acumulação de conhecimento, sendo necessários investimentos na qualidade da educação para possibilitar o salto qualitativo, conforme advoga a teoria do efeito do valor barreira (threshold effect); e iii) a proxy de estoque de capital humano construída, apesar de conter algumas limitaçóes - como a base de dados, RAIS, que considera apenas o mercado formal de trabalho, e os coeficientes de retorno da escolaridade utilizados na equação (2) - se apresentou consistente, podendo ser indicada como modelo para trabalhos futuros que visem considerar estas limitaçóes.

Em síntese, o estudo contribui para ampliar o conhecimento sobre o crescimento econômico dos municípios, que dada a disparidade da dinâmica municipal brasileira demonstra a necessidade de ampliar este tipo de pesquisa para uma melhor compreensão das diferenças municipais de longo prazo. 


\section{Referências bibliográficas}

AGHION, P.; HOWITT, P. A Model of Growth Through Creative Destruction.

Econometrica, New York, v. 60, p. 323-351, March/1992.

\section{ALEXANDRE, M.; BIDERMAN, C.; LIMA, G. T. Distribuiçâo regional do crédito bancário e convergência no crescimento estadual brasileiro. In: XXXII Encontro Nacional de Economia (ANPEC-Nacional), 2004, João Pessoa - PB. Disponível em < http://www.anpec.org.br/ encontro_2004.htm >. Acesso em: 15 maio 2006.}

ARELLANO, M; BOND, S. Some tests of specification for panel data: Monte Carlo evidence and an application to employment equations. Review of Economic Studies, v.58, p.277-297, 1991.

ARELLANO, M; BOVER, O.

Another look at the instrumental variables estimation of errorcomponent models. Journal of Econometrics, v. 68, p.29-51, 1995.

BALTAGI, B. H. Econometric analysis of panel data. 3th edition. New York: Wiley, 2005, 314 p.

BARRO, R.; LEE, J. W. International comparisons of educational attainment. Journal of Monetary Economics, v. 32, p. 363$394,1993$.
BARRO, R. J.; SALA-I-MARTIN, X. Economic growth. New York: McGraw Hill, 1995. 608 p.

BECK, T.; LEVINE, R.; LOAYZA, N. Finance and the sources of growth. Journal of Financial Economics, v.

58, p. 261-300, 2000.

BENHABIB, J.; SPIEGEL, M. The role of human capital in economic development: evidence from aggregate cross-country data. Journal of Monetary Economics, v. 34, n. 2, p. 143-173, 1994.

BERNANKE, B. S.; BLINDER, A. S. Credit, money, and aggregate demand. American Economic Review, v. 78, n. 2, p. 435-439, may/1988.

BERNANKE, B. S.; GERTLER, M. Inside the black box: the credit channel of monetary policy transmission. NBER Working Papers Series, n. 5146, jun/1995.

BLINDER, A. S.; STIGLITZ, J. E. Money, credit constraints, and economic activity. American Economic Review, v. 73, n. 2, p. 297-302, may/1983.

\section{BLUNDELL, R.; BOND, S}

Initial conditions and moment restrictions in dynamic panel data models. Journal of Econometrics, $\mathrm{n}$. 87, p. 115-143, 1998a.
BLUNDELL, R.; BOND, S. GMM estimation with persistent panel data: an application to production functions. The Institute for Fiscal Studies Working Papers, n. w99/4, sep. 1998 b.

CANGUSSU, R.C.; SALVATO, M. A. ; NAKABASHI, L. . Uma análise do capital humano sobre o nível de renda dos estados brasileiros: MRW versus Mincer. Estudos Econômicos. Instituto de Pesquisas Econômicas, v. 40, n. 1, p. 153 183,2010 .

CHAGAS, A. L. S.; TONETO JR., R. Fatores determinantes do crescimento local: evidências a partir de dados dos municípios brasileiros para o período 1980-1991. Revista Pesquisa e Planejamento Econômico, v. 33, p. 349-385, ago. 2003.

DIAS, J.; ARAUJO, E. C. de. Endogeneidade do setor financeiro e crescimento econômico: uma análise empírica para a economia brasileira (1980 a 2003). Revista Economia Contemporânea, v.10, n.3, p.575609, 2006.

DIAS, J.; DIAS, M. H. A .

Crescimento econômico, emprego e educação em uma economia globalizada. Ed. Eduem/UEMPR, Maringá-PR, 1999. 89 p.
DIAS, J.; MCDERMOTT, J. Aggregate Threshold Effects and the Importance of Human Capital in Economic Development. In. XXV Encontro Brasileiro de Econometria, Porto Seguro-BA, 2003.

DIAS, J.; DIAS, M. H. A.; LIMA F. F. de. Crescimento econômico e nível de escolaridade: teoria e estimativas dinâmicas em painel de dados. In: XXXIII Encontro Nacional de Economia, Natal-RN, 2005.

FAVERO, C. A .; GIAVAZZI, F. G.; FLABBI, L. The transmission mechanism of monetary policy in Europe: evidence from banks' balance sheets. NBER Working Papers Series, n. 7231, jul. 1999.

FERREIRA, P. C.; MALLIAGROS, T. G. Impactos produtivos da infraestrutura no Brasil: 1950-1995. Revista Pesquisa e Planejamento Econômico, n. 2, p. 315-338, ago. 1998.

GERTLER, M.; GILCHRIST, $S$. Monetary policy, business cycle, and the behavior of small manufacturing firms. Quartely Journal of Economics, v. 59, n. 2, p. 309-340, may 1994.

GLAESER, E. L. et al. Economic growth in a cross-section of cities. NBER Working Paper Series. n. 5013, feb 1995. 
HALL, R. E.; JONES, C. I. Why do some countries produce so much more output per worker than others? Quartely Journal of Economics, v. 114, n. 1, p. 83-116, feb 1999.

HAUSMAN, J. A. Especification Tests in Econometrics.

Econometrica, v. 46, p. 1251-1272, 1978.

HSIAO, C. Analysis of panel data. $2^{\text {nd }}$ edition. Cambridge, UK: Cambridge University Press, 2003. 366 p.

KING, R. G.; LEVINE, R. Finance and growth: Schumpeter might be right. Quarterly Journal of Economics, v. 108, n. 3, p. 717-721, aug 1993 .

KOMAN, R.; MARIN, D. Human capital and macroeconomic growth: Austria and Germany 1960-1997: an update. University of Munich, Working Paper 10, 1999.

KRUEGER, A. B.; LINDAHL, M. Education for growth: why and for whom? Journal of Economic Literature, v. XXXIX, p. 1101-1136, dec 2001.

LAM, D.; SCHOENI, R. Effects of family background on earnings and returns to schooling: evidence from Brazil. Journal of Political Economy, v. 101, n. 4, p. 710-740, 1993.

LAU, L. J.; JAMISON, D. T.; LIU, S. C.; RIVKIN, S. Education and economic growth: some crosscountry evidence from Brazil. Journal of Development Economics, v. 41, n. 1, p. 45-70, June 1993.

LEVINE, R.; LOAYZA, N.; BECK,
T. Financial intermediation and growth: causality and causes. Journal of Monetary Economics, $\mathrm{n}$. 46, p. 31-77, aug 1999.

LEVINE, R. Financia

development and economic growth: views and agenda. Journal of Economic Literature, v. 35, n. 2, p. 688-726, jan 1997.

LUCAS, R. On the mechanics of economic development. Journal of Monetary Economics, v. 22, p. 3-42, feb 1988.

MANKIW, N. G.; ROMER, D.; WEIL, D.N. A contribution to the empirics of economic growth. Quartely Journal of Economics, $\mathrm{n}$. 107, v. 2, p. 407-437, may 1992.

MARQUES, H. A nova geografia econômica na perspectiva de Krugman: uma aplicação às regiôes europeias. Working papers Centro de Estudos da União Européia, n. 7, Universidade de Coimbra, 2001. Disponível em: <http://www4.fe.uc.pt/ceue/ working_papers/ihelena.pdf >. Acesso em: 5 mar. 2007.

MATOS, O. C. de.

Desenvolvimento do sistema financeiro e crescimento econômico no Brasil: evidências de causalidade. Trabalhos para discussão do Banco Central, n. 49 , set 2002 .

MINCER, J. Schooling, experience, and earnings. New York:

Columbia University Press, 1974.

MISHKIN, F. S. The channels of monetary transmission: lessons for monetary policy. NBER Working Papers Series, n. 5464 , feb 1996.
NAKABASHI, L.; FELIPE, E. Capital Humano nos Municípios Paranaenses. Revista Análise Econômica (UFRGS), v. 25, n. 47, p. 7-22, 2007.

OLIVEIRA, C. Externalidades espaciais e o crescimento econômico das cidades do estado do Ceará. Revista Econômica do Nordeste, v. 36, n. 3, jul-set 2005.

PAGANO, M. Financial markets and growth: an overview.

European Economic Review, v. 37, p. $613-622,1993$

\section{PIRES, M. C. C. Crédito e} crescimento econômico: evidências para os municípios brasileiros.

VIII Encontro de Economia da Regiāo Sul - ANPEC-SUL, Porto Alegre-RS, 2005. Anais do VIII Encontro de Economia da Região Sul - ANPEC-SUL, Porto AlegreRS, 2005.

PSACHAROPOULOS, G. Returns to investment in education: a global update. Working Papers Series, 1067, jan/1993.

PÔRTO JÚNIOR, S. S. RIBEIRO, E. P. Dinâmica de crescimento Regional - uma análise empírica para a região Sul. Revista Econômica do Nordeste, Fortaleza-CE, v. 31, p. 454-483, 2000.

PORTUGAL, M. S., SOUZA, N. J. Fatores de crescimento da região sul, 1960/1995. Economia Aplicada, v. 3, n. 4, p. 577-613, 1999.

RAJAN, R. G.; ZINGALES, L. Financial dependence and growth. American Economic Review, v. 88 , n. 03, p. 559-586, jun 1998.
ROMER, P. Endogenous technological change. The Journal of Political Economy, v. 98, n. 5, p. 71-102, 1990.

SACHSIDA, A.; LOUREIRO, P. R. A .; MENDONÇA, M. J. C. de. Um estudo sobre retorno e escolaridade no Brasil. Revista Brasileira de Economia, v. 58, n. 2 p. 249-265, abr-jun 2004.

SOBRINHO, N. F. S. Uma avaliação do canal de crédito no Brasil. 25 Prêmio BNDES de Economia, Rio de Janeiro: BNDES, 2003. 68p.

SOLOW, R. M. A contribution to the theory of economic growth. Quartely Journal of Economics, $\mathrm{n}$. 70, v. 1, p. 65-94, feb 1956.

STIGLITZ, J. E.; WEISS, A.

Credit rationing in markets with imperfect information. American Economic Review, v. 71, n. 03, p. 392-410, jun 1981.

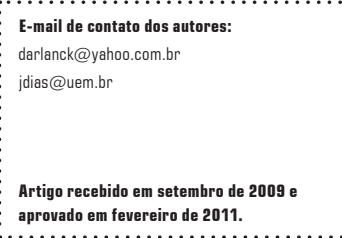

aprovado em fevereiro de 2011. 
